\title{
A apologia do consumo de bebidas alcoólicas e da velocidade no trânsito no Brasil: considerações sobre a propaganda de dois problemas de saúde pública
}

\author{
The promotion of alcoholic beverage consumption and traffic speed in Brazil: \\ considerations on the advertising of two public health problems
}

\author{
Ilana Pinsky ${ }^{1}$, Roberto Victor Pavarino Filho ${ }^{2}$ \\ ${ }^{1}$ Unidade de Pesquisa em Álcool e Drogas (UNIAD), Departamento de Psiquiatria, Universidade Federal de São Paulo (UNIFESP), São \\ Paulo, SP. ${ }^{2}$ Centro de Formação de Recursos Humanos em Transportes (CEFTRU), Universidade de Brasília (UnB), Brasília, DF. \\ Apoio financeiro: FAPESP, projetos n. 2003/06250-7 e 2004/13564-0.
}

\section{Resumo}

Os acidentes de trânsito, muitas vezes relacionados com excesso de velocidade, e os problemas decorrentes do consumo de bebidas alcoólicas são dois importantes problemas de saúde pública no Brasil. Esses problemas podem estar associados, como no caso do dirigir alcoolizado, mas também se apresentam de maneira independente. Entre os diversos fatores que impactam nesses problemas encontra-se a propaganda de estímulo (comerciais). A influência da propaganda em várias questões de saúde, incluindo consumo de álcool e segurança no uso de veículos, tem um papel que recentemente está sendo mais estudado e compreendido. Setores públicos e privados no Brasil têm influência na regulamentação da propaganda, que é ainda principalmente exercida através do exercício da auto-regulamentação. O presente artigo apresenta um quadro geral sobre o assunto e, diante dos prejuízos de ordem social e econômica advindos do consumo de bebidas e dos acidentes, propõe-se a discutir o papel que vem sendo exercido pelos meios de comunicação, sua responsabilidade social e os limites da autoregulamentação.

Descritores: Acidentes de trânsito, velocidade, mídia, álcool e propaganda.

\begin{abstract}
Traffic accidents, which are often associated with speeding, and the problems associated with consumption of alcoholic beverages are two major public health concerns in Brazil. These problems may be associated, as in the case of drunk driving, but they also occur independently. Commercial advertising is one of the factors that have an impact on these issues. The influence of advertising on many health issues, including alcohol consumption and traffic safety plays a role that has been continuously investigated and understood. Public and private sectors in Brazil have an influence on the advertising regulation, which is still mainly performed by industry self-regulation. This paper presents a general framework on the subject. In addition, faced with the social and economic hazards resulting from alcohol consumption and traffic accidents, it discusses the role of communication means, its social responsibility and the limits of self-regulation.
\end{abstract}

Keywords: Traffic accidents, speed, media, alcohol and advertising.

\section{Correspondência:}

Ilana Pinsky, Rua Prof. Henrique Neves Lefevre, 71 casa 4, Brooklin, CEP 04637-000, São Paulo, SP. E-mail: ilanapinsky@uol.com.br 


\section{Introdução}

Os acidentes de trânsito e as conseqüências do consumo de bebidas alcoólicas estão entre os principais problemas de saúde pública no Brasil. Esses problemas podem estar associados, como no caso do dirigir alcoolizado, mas também se apresentam de maneira independente.

Atualmente, há diversos levantamentos sobre o consumo de bebidas alcoólicas no Brasil e indícios importantes do peso desse hábito na saúde pública. Apenas para citar dados mais amplos, desde a década de 80 , foram feitos cinco levantamentos entre estudantes de ensino fundamental e médio, um mesmo número de estudos entre crianças em situação de rua, dois levantamentos domiciliares e vários seguimentos do índice de internações por conta de dependência química ${ }^{1}$. Além disso, em 2007, devem ser concluídos um estudo em várias cidades sobre o dirigir alcoolizado e um levantamento nacional, com amostra probabilística, sobre os padrões de consumo do álcool.

Os resultados desses vários estudos apontam para a bebida alcoólica como uma substância psicotrópica bastante conhecida pelos adolescentes, com uma idade média de início do uso de pouco mais de 12 anos de idade $^{2}$, ou seja, bem antes da idade legal para consumo.

Se já há alguma tradição em levantamentos epidemiológicos referentes ao consumo de bebidas alcoólicas, as informações sobre os acidentes de trânsito, embora existentes, costumam ser deficientes. Há, entretanto, certo consenso entre especialistas da área que o número de mortos no trânsito do país dificilmente seria inferior a 30 mil pessoas por ano, enquanto o total de feridos estaria próximo a $400 \mathrm{mil}$ indivíduos. Esse total de óbitos equivale a aproximadamente o número de homens que morre vítima de doenças infecciosas e parasitárias no país ou pouco mais da metade das mulheres brasileiras acometidas por neoplasias, que consistem na segunda maior causa de morte no país ${ }^{3}$.

Os traumas no trânsito representam entre 1 e $2 \%$ do PIB das economias nacionais ${ }^{4}$, sendo que $90 \%$ das mortes ocorrem em países de baixa e média renda, onde as populações mais pobres - exatamente as de menor acesso aos atendimentos após os traumas - conformam a maioria das vítimas.

No país, os traumas em transportes terrestres respondem pelo segundo lugar entre as mortes por causas externas (onde se incluem homicídios e acidentes diversos). Afora a desestruturação de núcleos familiares, o sofrimento e outras conseqüências de difícil mensuração, a soma dos custos relacionados aos conflitos envolvendo eventos como colisões, quedas e atropelamentos nas vias urbanas e rodovias brasileiras beiram, segundo estudos publicados pelo Instituto de
Pesquisa Econômica Aplicada (IPEA) entre 2003 e 2006, R\$ 30 bilhões a cada ano ${ }^{5}$. De acordo com o IPEA, a maior parte dos prejuízos refere-se à perda de produção associada à morte das pessoas ou à interrupção de suas atividades, seguida dos custos de cuidados em saúde e dos associados aos veículos.

Existem vários fatores que contribuem para esses altos índices de problemas relacionados ao álcool e aos acidentes de trânsito. No caso dos acidentes, estes, em geral, ocorrem como resultado da conjunção de alguns fatores relacionados ao ambiente físico (natureza/condições do espaço de circulação), ao veículo (suas limitações ou falhas) e às pessoas que utilizam as vias (comportamento, educação, perícia). Ligada a essa última variável (comumente entendida como fator "humano"), há a influência de uma ambiência político-social relacionada à percepção que um indivíduo tem da probabilidade de sanção. Ou seja, a omissão do poder público e a impunidade, por exemplo, podem ser entendidas como fatores que favorecem a ocorrência de acidentes.

Várias situações de ordem semelhante influenciam no aumento dos problemas relacionados ao consumo de bebidas alcoólicas. Assim, uma legislação frouxa e pouco fiscalizada (leis pouco específicas, poucos bafômetros, quantidade insuficiente de policiais ou fiscais) e o fácil acesso aos produtos alcoólicos (seja pelos horários de venda, quantidade de pontos-de-venda, preço do produto) são elementos centrais para o entendimento dos números apresentados acima. Outros fatores incluem aspectos sociofamiliares (tolerância excessiva em relação ao consumo de álcool, consumo freqüente por figuras próximas, como pais e amigos, etc.).

Mais recentemente, pesquisas têm investigado a maneira pela qual a propaganda e a mídia, de maneira geral, retratam questões de saúde pública. Essa literatura tem analisado desde comportamentos como a violência (análise de programas e videogames violentos), a obesidade infantil (propaganda de produtos hipercalóricos) e o consumo de cigarros (como o cinema, a TV e as propagandas tratam da questão) até a saúde bucal ${ }^{6,7}$. Boa parte dessa literatura tenta entender, de maneira descritiva, partindo de vários ângulos, a associação entre questões de saúde e meios de comunicação. Atualmente, um corpo de pesquisa tem se formado, principalmente na área de violência, consumo de tabaco e bebidas alcoólicas, para avaliar o impacto dos programas e da propaganda em problemas associados a esses comportamentos s,8,9. $^{6 .}$.

Pelo ângulo político, alguns órgãos governamentais nacionais parecem estar se interessando mais em fiscalizar o conteúdo de anúncios publicitários. Assim é que órgãos como o Ministério Público Federal, o Procon, a Agência de Vigilância Sanitária e o Congresso têm atuado no sentido de regulamentar e proibir propagandas ${ }^{10}$. Esse movimento, evidentemente, é 
criticado pelas agências de propaganda e órgãos representativos, que se organizam em torno de uma autoregulamentação de seu trabalho.

O presente artigo propõe-se a discutir a contribuição da propaganda de bebidas alcoólicas e de veículos, com foco na questão do incentivo à velocidade, nos problemas relacionados decorrentes. Pretendemos apresentar, resumidamente, a literatura atual sobre os efeitos da propaganda, a legislação brasileira na área e dar exemplos das dificuldades de auto-regulamento do setor.

\section{Veículos automotores, velocidade e propaganda}

Em vários ditos “acidentes”, a energia do choque é proporcional ao quadrado da velocidade - o que faz com que a força e os danos de uma colisão aumentem em uma proporção bem maior à medida que a velocidade aumenta. A questão é muito mais grave, entretanto, quando os choques se dão entre corpos de desproporção gritante, como entre carros e ciclistas ou nos atropelamentos. No trânsito, é comum que a velocidade seja apontada como um dos principais fatores envolvidos nos acidentes, pois, mesmo não sendo a única entre as diversas variáveis que contribuem para um evento, ela, de fato, potencializa os danos advindos dos demais fatores que estejam envolvidos nos desastres. Ou seja, quaisquer que sejam os elementos tidos como responsáveis pela ocorrência do evento - falha das pessoas diretamente envolvidas, falha mecânica ou más condições da via -, a intensidade dos danos resultantes também aumenta quanto maior a velocidade desenvolvida. Portanto, é compreensível que boa parte das medidas de segurança centrem-se no controle da velocidade praticada - o que, em geral, traz resultados verificáveis (diminuição da morbimortalidade e da gravidade dos danos).

Os limites de velocidade, no entanto, prescrevem um comportamento de difícil aceitação em uma ambiência de mudanças sociais, tecnológicas e econômicas rápidas. Em um mundo e em um tempo onde eficiência é sinônimo de celeridade, onde as coisas são boas quando são rápidas (ou ainda: porque são rápidas), os limites de velocidade vigentes nas ruas parecem inaceitáveis. Além disso, um autor ${ }^{11}$ aponta ainda haver certa "relativização" do conceito de velocidade, de modo a permitir que um condutor se paute por parâmetros autoreferenciados quanto ao que seriam limites razoáveis.

O estado de direito que limita a velocidade nas vias a $X \mathrm{~km} / \mathrm{h}$, por sua vez, é o mesmo que permite a fabricação, o comércio e a propaganda dos carros que desenvolvem até $3 \mathrm{X} \mathrm{km} / \mathrm{h}$, afrontando a razão. Paradoxos como esses, assim, prenunciam conflitos de valores.
Marin \& Queiroz ${ }^{12}$ assinalam a relação da velocidade com a experiência dos sentimentos de grandeza e fantasia de onipotência, identificando no automóvel uma compensação para egos angustiados e apáticos. Observam, ainda, a influência da publicidade sobre o comportamento e formação de valores e, particularmente, em relação aos anúncios que associam carros velozes à virilidade, significativa influência no grupo de risco de jovens motoristas.

Nos EUA, em 1998, o Insurance Institute of Highway Safety (IIHS), em uma pesquisa encomendada ${ }^{13}$, analisou uma amostra de comerciais de automóveis nas décadas de 80 e 90 . No levantamento, o tema predominante constatado é a performance dos veículos, referente ao desempenho, potência e velocidade dos carros - assunto que aparece em um percentual oito vezes maior que o da segurança. O IIHS, que aborda constantemente o tema velocidade em suas publicações periódicas, continuou a fazer o monitoramento dos comercias de automóveis na TV norte-americana, constando, no ano de $2003^{14}$, que os mesmos apelos à performance dos carros continuam a ser a forma mais recorrente de se vender carros. Entre os exemplos de propaganda observados no período, um Mercedes é perseguido por motocicletas e um helicóptero. Seguindo-se à cena de perseguição cinematográfica, a mensagem: "para se alcançar um (Mercedes), só tendo um”.

No Brasil, assim como em vários outros países, a indústria automotiva investe pesadamente em publicidade, onde os comerciais em TV recebem a maior parte dos investimentos. Enoki \& Santos ${ }^{15}$ assumem como hipótese o fato de as mensagens publicitárias explícitas ou implícitas - reforçarem valores que levam as pessoas a conduzir os veículos de forma agressiva, colocando em risco tanto a vida do condutor como a de terceiros. Como na pesquisa do IIHS norte-americano, os autores procederam a análises de uma série de comerciais de automóveis veiculados no Brasil e notaram que os aspectos "negativos" (por exemplo: sarcasmo, rivalidade, velocidade, transgressão) sobrepujam os entendidos como "positivos" (cuidado, estabilidade, segurança, solidariedade) e outros entendidos como "ambivalentes".

Seriam infindáveis os exemplos dos valores negativos propagados. Mas para ficarmos em apenas alguns, temos que o Departamento de Trânsito do Rio Grande do Sul (Detran-RS) ${ }^{16}$ entrou, em 2005, com representações contra campanhas publicitárias de veículos pick-up publicadas em revista de grande circulação nacional com chamadas como "Homem que é homem não buzina: assusta o carro da frente" ou "Faça parte de uma minoria esmagadora", acompanhadas por fotos tomadas de ângulos que enfatizam a agressividade dos veículos. 
O Detran-RS, a propósito, já havia entrado com representações como essa em outras ocasiões (nem sempre com sucesso). O portal da Secretaria de Justiça e Segurança desse estado refere outras campanhas, como a de uma indústria de pneus, veiculada em dezembro de 2005, com a chamada: "Pode soltar os cavalos"; a campanha de um automóvel, em maio de 2004, com a assertiva: "A vida começa aos 18, quando você já pode dirigir. Mas fica mais emocionante aos 120 ”; e a propaganda de certa gasolina, no final de 2005, com o mote: "O prazer de dirigir em alta octanagem”. Os anúncios publicitários, segundo o Detran-RS, eram agressivos e induziam o consumidor a utilizar seu veículo em alta velocidade, de maneira irresponsável e inconseqüente, avesso à segurança pública, comparando um carro de passeio a um carro da Fórmula 1.

Como se nota, a apologia da velocidade não se restringe aos fabricantes de veículos, mas a toda uma indústria a ela relacionada (equipamentos fundamentais, acessórios, combustíveis, etc.) e mesmo à indústria de serviços e entretenimentos.

\section{Bebidas alcoólicas e propaganda}

Até alguns anos, os resultados dos estudos de impacto eram bastante frágeis, com dificuldades de efetivamente provar a ligação entre a propaganda de álcool e o aumento do consumo desse produto ${ }^{17}$. Apesar de intuitivamente parecer que essa ligação é evidente (por qual outra razão se gastaria milhões com propaganda?), o argumento da indústria do álcool é que a propaganda é um instrumento de escolha de marcas para o indivíduo que já é um consumidor. Como a metodologia dessa área é extremamente complexa (há muitos fatores que se autoinfluenciam ao mesmo tempo, é difícil medir a exposição ou mesmo a quantidade de propaganda, etc.), por anos as pesquisas dessa área não avançaram muito as políticas públicas. Atualmente, já se pode dizer que os estudos existentes resultaram em um corpo de conhecimentos importantes na área.

A partir da década de 90 , começaram a ser publicados artigos com metodologia mais apurada, com a conseqüência do avanço do entendimento de como se dão esses efeitos da propaganda sobre o consumo. Dois livros-bíblia da área de políticas públicas do álcool, publicados em 1994 e em 2003, resumem os avanços feitos na área. A primeira publicação ${ }^{18}$ conclui que, além de diferenciar entre diferentes marcas, a propaganda de álcool "reforça atitudes pró-álcool, pode aumentar o consumo de álcool entre indivíduos que já bebem, desencorajar bebedores a reduzir ou parar o consumo e influenciar a formação de políticas públicas”(p. 169). O segundo livro ${ }^{8}$, já sob o efeito de uma indústria do marketing de bebidas alcoólicas mais globalizada e agressiva e contando com resultados mais aprimorados, é ainda mais incisivo em suas conclusões. Os autores analisam que: "Apesar da pesquisa na área de propaganda do álcool provavelmente se manter altamente controversa, há algumas evidências que o marketing pode ter um impacto sobre os jovens (...) As pesquisas indicam a influência cumulativa da propaganda de álcool em formatar as percepções dos jovens sobre o álcool e as normas do beber. A propaganda do álcool predispõe os jovens a beber bem antes da idade legal para compra" (p. 183).

O Brasil iniciou apenas recentemente uma linha de pesquisa nessa área. Em 1994, um dos presentes autores analisou os temas e a freqüência de propagandas de televisão de bebidas alcoólicas ${ }^{19}$. O estudo mostrou que as propagandas e vinhetas (chamadas de poucos segundos para mostrar patrocínio de um programa) de bebidas alcoólicas eram mais freqüentes do que as de cigarro (na época, não havia a lei que proibia sua veiculação, citada abaixo), de bebidas não-alcoólicas e medicamentos. Os temas mais freqüentes nas 190 propagandas analisadas versavam sobre relaxamento, simbolismo nacional, conformidade, amizade e humor. Fora isso, há uma série de estudos da área sendo elaborados, dentro de um projeto aprovado pela Fundação de Amparo à Pesquisa do Estado de São Paulo (FAPESP), mas os primeiros resultados só devem ser apresentados em aproximadamente 1 ano.

As inúmeras investigações na área feitas em diversos países concluem que os efeitos da propaganda no consumo de álcool por jovens são uma decorrência, principalmente, da exposição, apreciação e reconhecimento (lembrança) que esses indivíduos têm sobre as mesmas ${ }^{20}$. De acordo com esses parâmetros, uma rápida olhada nos dados existentes no país já sugere a contribuição que a propaganda de bebidas alcoólicas pode ter nos problemas relacionados ao consumo excessivo de álcool. Uma pesquisa mensal feita pela Datafolha e publicada regularmente na revista Meio e Mensagem para referência dos próprios profissionais de propaganda mostra que duas ou três marcas de cerveja estão entre as 10 propagandas mais lembradas e mais apreciadas pelo público, independentemente da faixa etária, há anos. Já a pesquisa nacional probabilística sobre os padrões de consumo de álcool citada acima, em uma análise ainda preliminar, aponta que $78 \%$ dos adolescentes referiam ter sido expostos quase todos os dias, até mais de uma vez por dia, à propaganda de álcool. Esses números baixavam para 23\% quando perguntavase sobre a exposição a programas de prevenção, segundo o levantamento da Unidade de Pesquisa em Álcool e Drogas (UNIAD), da Secretaria Nacional Antidrogas (SENAD) (comunicação pessoal). É importante mencionar que esses dados não surpreendem, já que 
milhões são gastos todo ano apenas em investimentos publicitários (ou seja, no pagamento aos meios de comunicação) de cerveja no Brasil.

Colocado esse quadro, o que existe em termos regulatórios no Brasil? A próxima seção apresenta a situação da legislação brasileira e da autoregulamentação da indústria da propaganda em relação à propaganda de automóveis e de bebidas alcoólicas.

\section{Leis e regulamentos básicos da propaganda brasileira afetas à publicidade de álcool e de veículos automotores}

Em relação à regulamentação da propaganda brasileira, destacam-se, entre as leis e regulamentos afetos à matéria aqui discutida, o Código Brasileiro de Auto-Regulamentação Publicitária, do Conselho de Auto-Regulamentação Publicitária (CONAR); a Lei n ${ }^{\circ}$ 4680/65, relativa ao exercício da profissão de publicidade; o Código de Ética dos Profissionais de Propaganda (referido no art. 17 da Lei n ${ }^{\circ}$ 4680/65 mencionada); e o Código de Defesa do Consumidor (CDC) - Lei n ${ }^{\circ} 8.078 / 90^{21}$

O Código de Ética dos Profissionais de Propaganda, por exemplo, afirma que o profissional, para atingir seus fins, jamais deverá induzir o povo ao erro, tampouco lançar mão da inverdade ou disseminar a desonestidade e o vício ${ }^{22}$.

$\mathrm{O} \mathrm{CDC}^{23}$ traz elementos que dizem respeito tanto à propaganda de carros quanto à de álcool. Em algumas seções, o CDC faz menção direta à publicidade e proíbe toda "publicidade enganosa ou abusiva" capaz, mesmo por omissão, de induzir ao erro a respeito da natureza, características e quaisquer outros dados de produtos e serviços que incitem à violência ou ao um comportamento prejudicial ou perigoso à sua saúde ou segurança. Sobre esse último aspecto, com efeito, afirma-se a obrigação do fornecedor de produtos e serviços de divulgar clara e ostensivamente informação relacionada às características, composição e riscos que os produtos trazem particularmente aqueles potencialmente nocivos ou perigosos à saúde ou segurança.

Além dos regulamentos apresentados acima, é importante mencionar a Lei Federal no 9.294, de 1996, que traz regras mais específicas às propagandas de bebidas alcoólicas e regulamenta também medicamentos, produtos agrícolas e tabaco. Para efeito dessa lei, no entanto, as bebidas alcoólicas são apenas aquelas com um grau alcoólico superior a $13^{\circ} \mathrm{GL}$, ou seja, EXCLUINDO cerveja (de longe, o produto alcoólico com maior gasto em propaganda) e a maioria dos vinhos. Seu principal acréscimo, no caso das bebidas alcoólicas (com a restrição citada acima), é restringir os horários de veiculação das propagandas entre 21 e 6 horas. As vinhetas, no entanto, são permitidas em qualquer horário. Uma nova lei, de $\mathrm{n}^{\circ}$ 10.167, foi aprovada em 2000 para substituir a lei acima. Essa regulamentação basicamente proibiu a propaganda de tabaco em todas as mídias, exceto nos locais de venda. Apesar de essa nova lei não incluir o álcool em seu texto, parece claro que a partir daí o clima político em relação à propaganda de bebidas alcoólicas também mudou. Atualmente, existe um grande número de projetos de lei, sugerindo vários níveis de restrições.

Além da legislação oficial, a propaganda brasileira é regulamentada, como citado acima, pelo Código do CONAR. A exemplo de vários países, o setor de propaganda brasileira organizou-se e, a partir do início da década de 80, começou a editar regras de "comportamento" interno, na tentativa de evitar ingerência externa (leia-se do Governo). O código é atualizado (de acordo com as tendências da sociedade, do momento político, do ocorrido em outros países, etc.) a cada poucos anos. Além do seu corpo geral, o código possui anexos referentes a produtos específicos. Em relação aos produtos discutidos nesse artigo, há atualmente três anexos (“A”, “P” e “T) para bebidas alcoólicas e um (“O”) para veículos automotores.

O Código do CONAR para as bebidas alcoólicas é mais específico do que a legislação federal. Além de referir-se a todos os tipos de álcool (inclusive cerveja), propõe regras de conteúdo um pouco mais claras e acrescenta a obrigatoriedade de uma mensagem de advertência em relação ao consumo excessivo em qualquer propaganda. O básico mantém-se o mesmo; ou seja, as cervejas e vinhos continuam eximidos de submeter-se ao limite de horário que as outras bebidas alcoólicas cumprem. No caso do anexo "O”, referente à propaganda de veículos automotores, o código veta sugestões de utilização do veículo que possam pôr em risco a segurança pessoal do usuário e de terceiros, tais como ultrapassagens não permitidas em estradas, excesso de velocidade, não-utilização de acessórios de segurança, desrespeito à sinalização, aos pedestres e às normas de trânsito de uma forma geral.

Entidades ligadas à indústria da propaganda apóiam veementemente a auto-regulamentação da área, utilizando argumentos sobre liberdade de expressão, mas querendo de fato evitar a interferência do Governo. Mas a auto-regulamentação da propaganda funciona?

\section{A auto-regulamentação da propaganda: além das palavras}

William Leiss, especialista em comunicação social relacionada a riscos, afirma, em um livro organizado por Rothe ${ }^{24}$, que, com a proeminência da comunicação 
de massa na vida pública, decorreram preocupações relacionadas aos impactos da mídia. Leiss resume as análises desses impactos em duas categorias: a dos efeitos intencionados e a dos não-intencionados. Entre os primeiros, aqueles resultantes de campanhas com comerciais têm sido os mais investigados, de maneira a subsidiar as estratégias de investimentos empresariais. Já os efeitos não-intencionados da mídia - aquilo que supostamente não se almejou, mas produziu certa conseqüência - seriam de interesse para os encarregados de políticas públicas. Em alguns países, a investigação desses efeitos pode subsidiar e fundamentar os controles da mídia por legislação imposta ou voluntariamente pelas indústrias. Exemplos seriam a promoção de condutas anti-sociais, a sub-representação (por exemplo: grupos étnicos) ou representações distorcidas de papéis e estereótipos.

Nos EUA, não obstante a Federal Communications Comission (órgão que detém autoridade sobre o teor das propagandas nas redes de TV norte-americanas) tenha determinado que as emissoras devam se pautar pelo "interesse público", argumentos em defesa da liberdade de expressão, como no Brasil, fazem com que casos flagrantes de promoção de comportamentos de alto risco na direção de veículos sejam rotineiros.

No caso brasileiro, o CONAR, não obstante ser desconhecido da maioria dos brasileiros, recebe reclamações onde alega-se desrespeito ao código (criado pelo próprio órgão). No que se refere à publicidade de automóveis, de nove julgamentos verificados por Santos \& Enoki ${ }^{15}$, em apenas três casos o CONAR recomendou alteração dos filmes, enquanto nos seis outros a reclamação foi arquivada. O que havia sido classificado como transgressão às leis de trânsito, na visão dos telespectadores, foi, no entender dos conselheiros, tido como "criatividade e engenhosidade por parte das agências de publicidade", fato que permitiu aos autores questionarem a isenção do Conselho de Ética (órgão que julga as reclamações dirigidas ao CONAR), composto majoritariamente por membros de agências de publicidade, anunciantes e mídia.

É simples constatar que o questionamento de Santos \& Enoki não é leviano, a partir da análise de uma série de comerciais feita no estudo que desenvolveram. Como exemplo, em um filme de 31 segundos anunciando o automóvel Audi A3, o veículo corta velozmente uma cortina de fumaça, em uma rua molhada em centro urbano, em cenas que intercalam curvas em alta velocidade e o interior de um teatro, onde as pessoas se acomodam nas cadeiras. A legenda, em fade-out, anuncia: "Grandes óperas não admitem um minuto de atraso". O anúncio, objeto de reclamação de consumidores, teve seu processo arquivado pelo CONAR. É difícil, nesse caso, saber o que é mais acintoso, se a imagem de um carro em via urbana com o velocímetro apontando $140 \mathrm{~km} / \mathrm{h}$ ou o parecer do relator do processo afirmando não ter identificado na peça "elementos que comprovam a velocidade excessiva”. A parte mais infame do acinte talvez fique por conta da legenda em letras minúsculas que aparece rapidamente no comercial: "Respeite os limites de velocidade".

Julgar que a velocidade explicitamente veiculada seria apenas uma impressão advinda de geniais "técnicas avançadas de cinematografia” demonstra como os pendores de quem julga faz a diferença. As regulamentações da Canadian Radio-Television and Telecommunication Commission (CRTC) para a veiculação de propaganda de cervejas e vinhos buscou estabelecer restrições a certas imagens. Pelo código canadense, por exemplo, é proibido tentar associar as bebidas a símbolos de status ou dar a entender, direta ou indiretamente, que a aceitação social, sucesso pessoal, negócios ou conquistas esportivas podem ser atingidas, engrandecidas ou reforçadas por meio do consumo de quaisquer dos produtos em foco.

O citado comunicólogo Willian Leiss (em Rothe ${ }^{24}$ ) refere estudos relacionados às concessões feitas a esta regulamentação. Neles, a comparação do conteúdo dos anúncios de TV com as intenções presumidas do regulamento revelou ter havido substancial cumprimento à interpretação literal de muitas das regulamentações. No entanto, argumenta, se alguns dos pré-requisitos estipulados fossem interpretados de maneira mais ampla, poderia se dizer que houve considerável desobediência aos preceitos em questão. Isso se deve, segundo Leiss, aos próprios regulamentos, que, diante da necessidade de cobrir uma vasta variedade de situações, recorrem a uma linguagem necessariamente generalizante (e, de certa forma, vaga), tornando a tarefa de escapulir dos preceitos do regulamento algo fácil, especialmente para os criativos profissionais das agências de publicidade.

$\mathrm{O}$ mesmo se constata no que se refere às propagandas de álcool. Analisando-se o próprio site do CONAR, onde os processos e resultados de vários anos são apresentados resumidamente, constata-se que são freqüentes as denúncias por desrespeito ao código. De fato, apenas em 2005, catalogou-se 32 denúncias, a maior parte das quais referente à indústria de cerveja. Em grande parte dos casos, a denúncia é apresentada pela própria indústria, no caso uma cervejaria concorrente. As razões para apresentação dos casos incluem, com destaque, aqueles classificados como de "respeitabilidade" e "responsabilidade social". O próprio CONAR, eventualmente, apresenta suas próprias denúncias, mas nem sempre é bem-sucedido em tirar a propaganda de álcool do ar. Apesar do grande número de denúncias e da preocupação do próprio órgão 
em fiscalizar e denunciar outros casos, uma rápida análise de propagandas recentemente veiculadas colocam dúvidas sobre a eficácia da autoregulamentação. Por exemplo, um anúncio duplo da Schincariol, veiculado em revistas, diz que agora não se levanta apenas um dedo para pedir a cerveja (em referência ao gesto utilizado por outra marca de cerveja), mas a mão inteira, já pedindo uma rodada. $\mathrm{O}$ aviso burocrático na vertical de uma das páginas para evitar o consumo excessivo é curioso, em vista da sugestão ao consumo de cinco doses de cerveja. Da mesma maneira, apesar de o código incluir (de modo bastante impreciso) um item para que "evite-se referências ao erotismo”, um número grande de propagandas incluem referências explícitas à sexualidade (na maioria das vezes, mesclada com humor, o que pode ser julgada por alguns como reduzindo o papel do erotismo).

\section{Discussão}

Não é propósito deste artigo - nem o espaço permite - discutir em que medida a mídia promove ou apenas reproduz valores. Tampouco se deseja atribuir somente aos anúncios atitudes e comportamentos no trânsito e no consumo de bebidas alcoólicas. No entanto, quantias astronômicas investidas na publicidade de produtos como bebidas e automóveis demonstram, em si, que setores acostumados a calcular rigorosamente a alocação de recursos não dispensariam tamanha atenção à propaganda sem assegurar-se do seu poder de influência. Além disso, no que se refere às bebidas alcoólicas, estudos científicos têm continuamente demonstrado o papel das propagandas não apenas no clima social, mas também sobre o próprio comportamento de consumo precoce e aumento do uso entre jovens ${ }^{8}$.

O clima político no Brasil em relação à propaganda de bebidas alcoólicas parece estar gradualmente se modificando. Vários setores do país começam lentamente a compreender o impacto do consumo nocivo de bebidas alcoólicas na saúde, economia e segurança do país. Do lado da saúde pública, há ao menos um movimento organizado por articulação de entidades da sociedade civil, a Aliança Cidadã pelo Controle do Álcool (ACCA), cuja meta é a aprovação de legislação que limite a publicidade de álcool nos meios de comunicação e em eventos esportivos, culturais e sociais. Em relação a medidas oficiais do Governo, em 2003, foi organizada uma comissão interministerial para propor medidas que resultassem em uma redução dos problemas relacionados ao álcool. Entre essas medidas, sugeriu-se a limitação da propaganda de bebidas alcoólicas, mas nada de efetivamente diferente do que já era realidade de fato se cumpriu. Mais recentemente, a Agência Nacional de Vigilância Sanitária (Anvisa) lançou um edital para consulta pública com o objetivo de restringir a propaganda do álcool. Essa proposta, tímida segundo opinião dos especialistas da área, tem sido atacada pela indústria do álcool e da propaganda com argumentos em relação à liberdade de expressão.

No trânsito, a visão das mortes e ferimentos como “acidentes” (frutos do acaso ou do destino) dificulta o tratamento da questão como algo que implique em responsabilidades e providências. Há mobilizações pontuais localizadas, quando da morte violenta de alguém no trânsito (por exemplo: uma comunidade fecha uma rua para protestar, queimando pneus, ou protesta durante o sepultamento de alguma vítima, exigindo justiça). Mas nem sempre se trata a questão de forma sistemática e organizada. Ainda se mantém certa condescendência se o autor do caso é uma celebridade. Em Brasília, em 1996, a campanha Paz no Trânsito envolveu, de forma inédita, a sociedade, o Governo e a mídia, implicando em uma drástica redução no número de mortos e feridos no trânsito. Mobilizações como essa se repetiriam em algumas outras cidades, em menor escala e com diferentes respostas e obstáculos, pois medidas de segurança também implicam em limitação na mobilidade irrestrita de muitos (radares, lombadas, etc.). A promulgação do novo Código de Trânsito Brasileiro, em 1997, poderia ser considerada, em certa medida, uma forma de organização da sociedade (por meio de seus representantes no Congresso e por grupos de pressão diversos) para buscar a redução da violência no trânsito. Alcançou-se, efetivamente, algum avanço, mas a situação ainda está longe do ideal.

De qualquer maneira, os números mostram que as medidas nacionais são ainda muito tímidas para atacar ambos os problemas e que o impacto na saúde pública é muito importante. Em um país escasso em recursos e, principalmente, em vontade política para lidar com essas situações, o enorme investimento publicitário adquire contornos mais relevantes. A verdade é que ainda estamos longe, no Brasil, de termos um balanço entre investimentos preventivos e de incentivo aos comportamentos de consumo de álcool e de velocidade no trânsito. Os já limitados recursos para a promoção da educação sofrem, ainda, contingenciamentos ou desvios de seus destinos. Nesse quadro, os educadores e comunicadores que operam em favor da segurança têm um trabalho penoso de promover uma revisão e reconstrução de valores, remando contra a prevalência de padrões de atitudes arraigados. Ademais, diferentemente das promoções comerciais (de carros ou bebidas), nem sempre o que se tem a dizer nas mensagens das campanhas 
preventivas é algo agradável, não sendo, por decorrência, algo sempre bem recebido. É, portanto, frustrante e contraproducente que, não bastassem as dificuldades inerentes a esse processo educativo, as políticas públicas tenham que enfrentar uma contrapropaganda tão explícita e poderosa.

No campo da segurança de trânsito, assim como no de problemas relacionados ao álcool, é comum, nas avaliações das estratégias de ação preventiva e nas discussões que buscam diagnosticar "o que funciona”, procederem-se equivocadas contraposições entre ações voltadas ao esforço legal (limitações, fiscalização, repressão e sanções punitivas) e às ações educativas. Argumentações clichês, como as que desprezam a educação, assim como as que afirmam ser necessário educar "ao invés” de punir (utilizada, não surpreendentemente, por infratores contumazes), impedem uma melhor percepção de que a ação repressiva e a ação educativa são, antes, mais complementares que antagônicas. Civilidade - vale lembrar - também se faz com repressão. Não, obviamente, a repressão brutal da "lei do mais forte", mas exatamente a repressão que impede que tal lei se estabeleça e que alguns ocupem o espaço público da forma que bem entendam, ameaçando a integridade de terceiros. Marin \& Queiroz ${ }^{12}$, analisando a situação da velocidade e acidentes de trânsito no Brasil, afirmam: “(...) A implementação de um programa consistente de educação no trânsito (...) é imprescindível. É também necessário um controle da propaganda, tanto daquela que associa a velocidade à vitalidade e à saúde, como da que associa ingestão de bebidas alcoólicas à liberdade e ao prazer”(p. 18).

Vale lembrar que, em nações que estão longe de sofrer complexos terceiro-mundistas (e tampouco se caracterizam por um totalitarismo anticapitalista), é legítimo se entender que uma sociedade tem o direito de se defender daquilo que julga ser pernicioso - e que isso pode ser entendido como mais do que somente $o$ acesso ao controle remoto da TV. E da mesma forma que é legítimo e - mesmo desejável - que na democracia uma atividade se auto-regulamente, é também legítimo que se questione se interesses corporativos ou financeiros estejam atropelando os interesses da sociedade como um todo.

Facilitar o acesso a preservativos, a alimentos saudáveis e promover ambientes livres do tabaco são medidas que ajudam mais do que simplesmente informar a população sobre os perigos da AIDS, do colesterol e do fumo. Assim como essa visão da promoção da saúde tem ganhado espaço junto às ações que limitavam-se à prevenção de riscos centradas no comportamento das pessoas ${ }^{25}$, as ações na área de segurança de trânsito, antes limitadas a culpar as vítimas pelas tragédias, e as do consumo do álcool, antes centradas apenas em medidas pouco efetivas (mas populares), como a prevenção em escolas, devem também caminhar no sentido de promover não somente um espaço mais seguro, mas uma ambiência social fundamentada na preservação. Nesse campo, reafirmase a importância dos meios de comunicação.

\section{Referências}

1. Galduróz JC, Caetano R. Epidemiologia do uso de álcool no Brasil. Rev Bras Psiquiatr. 2004;26(S1):3-6.

2. Galduróz JC, Noto AR, Fonseca AM, Carlini EA. V levantamento nacional sobre o consumo de drogas psicotrópicas entre estudantes do ensino fundamental e médio da rede pública de ensino nas 27 capitais brasileiras, 2004. São Paulo: Centro Brasileiro de Informações sobre Drogas Psicotrópicas; 2005.

3. Brasil, Ministério da Saúde, Secretaria da Vigilância em Saúde, Departamento de Análise de Situação em Saúde. Saúde Brasil 2005: uma análise da situação de saúde no Brasil. Brasília: Ministério da Saúde; 2005.

4. Peden M, ed. World report on road traffic injury prevention. Geneva: WHO; 2004.

5. Instituto de Pesquisa Econômica Aplicada, Associação Nacional de Transportes Públicos. Impacto social e econômico dos acidentes de trânsito nas aglomerações urbanas brasileiras: relatório executivo. Brasília: IPEA/ANTP; 2003.

6. Gomide PIC, Pinsky I. A influência da mídia e o uso das drogas na adolescência. In: Pinsky I, Bessa MA, eds. Adolescência e drogas. Contexto; 2004. p. 54-67.

7. Kline KN. A decade of research on health content in the media: the focus on health challenges and sociocultural context and attendant informational and ideological problems. J Health Commun. 2006;11(1):43-59.

8. Babor T, Caetano R, Casswell S, Edwards G, Giesbrecht N, Grahan $\mathrm{K}$, et al. Alcohol: no ordinary commondity. Oxford University Press; 2003.

9. Krugman DM, Quinn WH, Sung Y, Morrison M. Understanding the role of cigarette promotion and youth smoking in a changing marketing environment. J Health Commun. 2005;10(3):261-78.

10. MP, procon e até o congresso fiscalizam e punem propaganda. O Estado de S. Paulo 2006 Mar 27;B12.

11. Thielen, IP. Risk perception and speeding. In: Proceedings of the Extra Workshop International Cooperation on Theory and Concepts on Traffic Safety - ICTCT. Campo Grande: ICTCT; 2005. Disponível em: http://www.ictct.org/workshops/05-CampoGrande/ S2_Thielen1.pdf.

12. Marin L, Queiroz MS. A atualidade dos acidentes de trânsito na era da velocidade: uma visão geral. Cad Saude Publica. 2000;16(1):721.

13. Insurance Institute for Highway Safety. Car Ads Status Rep. 2000;35(8):1-8.

14. Insurance Institute for Highway Safety. Faster travel and the price we pay. Status Rep. 2003;38(10):1-7.

15. Enoki FK, Santos CB. Publicidade de automóveis no contexto da educação para o trânsito [Monografia de Especialização em Educação para o Trânsito]. Brasília: Universidade de Brasília. Faculdade de Tecnologia. Centro de Formação em Recursos Humanos em Transportes - Ceftru; 2004.

16. Rio Grande do Sul, Secretaria da Justiça e da Segurança. Detran-RS entra com representações contra campanhas publicitárias. Disponível em: http://www.sjs.rs.gov.br/portal/principal.php?action= imp_noticias\&cod_noticia $=5592$.

17. Iwaarden MJ. Public health aspects of the marketing of alcoholic drinks. In: Grant M, ed. Alcohol policies. Copenhagen: WHO; 1985. p. $45-55$.

18. Edwards G, Anderson P, Babor TF, Casswell S, Ferrence R, Giesbrecht N, et al. Alcohol policy and the public good. Oxford: Oxford University; 2004. 
19. Pinsky I, Silva MTA. A frequency and content analysis of alcohol advertising on Brazilian television. J Stud Alcohol. 1999;60(3):3949.

20. Grube JW, Waiters E. Alcohol in the media: content and effects on drinking beliefs and behaviors among youth. Adolesc Med Clin. 2005;16(2):327-43.

21. Sant'Anna A. Propaganda: teoria, técnica e prática. São Paulo: Pioneira Thomson; 2002.

22. Código de ética dos profissionais de propaganda. Disponível em: http://www.dhnet.org.br/direitos/codetica/codetica_brasil/ propagd.html.

23. Brasil, Ministério da Justiça. Código de Defesa do Consumidor (CDC) - Lei $\mathrm{n}^{\circ}$ 8.078, de 11 de setembro de 1990. Disponível em: http://www.mj.gov.br/DPDC/servicos/legislacao/cdc.htm.

24. Rothe JP. Challenging the old order: towards a new direction in traffic safety theory. New Brunswick: Transaction; 1990.

25. Tight M, Page M, Wolinski A, Dixey R. Casualty reduction or danger reduction: conflicting approaches or means to achieve the same ends? Trans Policy. 1998;5(3):185-92. 